OPEN ACCESS

Edited by: Aide Aracely Maldonado-Macías, Universidad Autónoma de Ciudad Juárez, Mexico

Reviewed by: Yolanda Baez-Lopez, Autonomous University of Baja California, Mexico Horacio Tovalin, National Autonomous University of Mexico, Mexico

*Correspondence: $X u$ Hongyi Xu steven_64@gmail.com

Specialty section: This article was submitted to Organizational Psychology, a section of the journal Frontiers in Psychology

Received: 13 February 2021 Accepted: 13 April 2021 Published: 01 July 2021

Citation:

Soomro SA, Gadehi AA, XU XH and Shaikh SA (2021) Job Stress and Burnout Among Employees Working in Terrorist-Ridden Areas.

Front. Psychol. 12:667488. doi: $10.3389 /$ fpsyg.2021.667488

\section{Job Stress and Burnout Among Employees Working in Terrorist-Ridden Areas}

\author{
Shuaib Ahmed Soomro ${ }^{1}$, Akhtiar Ali Gadehi ${ }^{2}$, Xu Hongyi Xu ${ }^{3 *}$ and Sarfaraz Ahmed Shaikh ${ }^{4}$ \\ ${ }^{1}$ Department of Business Administration, Sukkur Institute of Business Administration (IBA), Sukkur, Pakistan, ${ }^{2}$ Bahria \\ University Karachi Campus, Karachi, Pakistan, ${ }^{3}$ School of Management, Wuhan University of Technology, Wuhan, China, \\ ${ }^{4}$ Indus Center for Sustainable Development, Karachi, Pakistan
}

This article examines the relationship of effort-reward imbalance (ERI) on employee stress by considering job burnout (BO), organizational (in)justice (OJ), and sensitivity to terrorism (STT). This study uses the effort-reward imbalance (ERI) framework as a job stress model. After describing terrorism and a brief discussion on organizational justice and some of its challenges, we introduced "sensitivity to terrorism" as a moderator in the ERI framework. Using a 432 sample size of questionnaire data collected from two big cities where terrorist attacks are rampant and received during a period when terrorist attacks were at a peak. After analyzing data in EFA, results from the hierarchical regression analysis provided support for our developed model. Overall, the statistical model is significant $(p<0.05)$. We found significant relationships between $\mathrm{ERI}$ and facets of $\mathrm{BO}$. Organizational (in)justice mediated the influence of ERI on facets of $\mathrm{BO}$. We also found that STT significantly moderated ERI and facets of burnout. The article concludes with some implications and guidelines for future research.

\footnotetext{
Keywords: job stress and strain, organizational injustice, burnout - professional, psychology, terrorism salience, effort reward imbalance model
}

\section{INTRODUCTION}

Stress diminishes the ability to perform because of its adverse effect on health (Fischer et al., 2006; Marmot, 2015; Harlow and Lawler, 2018). Stress in the workplace emerges from external sources such as changes in political setups (Labrague et al., 2017), advancement in technology (Bliese et al., 2017; Carnall, 2018), changes in the economy (De Jonge and Dormann, 2017); and from within the organization due to lack of resources, organizational justice, gender, and ethnic bias.

Current work focuses on the internal and external issues that ignite stress levels with a specific focus on organizational justice, effort-reward imbalance, and acts of terrorism at or near the workplace (Czinkota et al., 2010). The act of terrorism complicates and slows down economic activities since it makes challenging for a workplace to function smoothly. Engaging employees in terrorism-ridden areas is a big challenge since terrorism adversely affects job commitment, produces turnover intentions, lowers performance, and ultimately ends in health problems (Hobfoll et al., 2007).

Incidents of terrorism foster uncertainty that affects employees and is considered one of the primary determinants of stress (Brandon and Silke, 2007). Uncertain factors are believed to be the fundamental determinant of job stress. Moreover, employment in terrorism-ridden areas is often physically and emotionally demanding when one compares the priceless value of life with rewards, such as compensation, fringe benefits, job security, personal accomplishment, and overall satisfaction, which lead to job stress. Increased direct and indirect incidents near and around 
workplaces have created work-life complications, affecting the performance of the organization as well as employee well-being (Canetti-Nisim et al., 2009; Malik et al., 2014).

The relationship between employee job stress working in terrorism-ridden areas is less explored (Bader et al., 2015). The extant literature on the effects of terrorism on employee behavior and the working practices of organizations is limited and empirical evidence is relatively low in the context of Pakistan (Soomro et al., 2020). The present study attempts to address this gap by studying Pakistan's businesses that are affected by terrorist incidents. This study uses the ERI framework and takes a focused view of incidents of discontinuous terrorism incidents around the workplace.

The aim of the study is first to describe the ERI framework, which provides a valuable approach to studying working environments in terrorism-ridden areas. Second, we suggest that organizational justice, characterized as the organization's behavior and the employee's resulting behavior, for example, employers making workers redundant, an employee may feel a sense of injustice with a consequent change in output and may increase burnout. We propose that a fair process of organizational justice will make employees more prone to work and experience less burnout at work.

\section{ERI AND JOB BURNOUT}

Siegrist (2016) developed the ERI model to identify the healthadverse effects of stressful psychosocial work and employment conditions in developed and rapidly developing countries. The word "effort" is used in its broadest sense to refer to all efforts the employee made, while the term "reward" is used to describe all rewards received in exchange for efforts. The imbalance between high effort and low rewards received is likely to have negative well-being, which increases stress (Siegrist et al., 2004; Lange et al., 2005; Van Vegchel et al., 2005; De Jonge et al., 2008). A balance between effort spent and reward received is likely to promote well-being and high health (Montano et al., 2016). The disequilibrium may cause a condition of emotional distress, which can prompt strain responses.

In an organizational context, Maslach and Jackson (1981) described burnout as an outcome of job stress. Long-lasting stress at work is often due to prolonged involvement and association with unfavorable and emotionally worrying working conditions (Ahola et al., 2009; Klein et al., 2010). It results from excessive demands at work, such as mental distress, sleeplessness, anger, rumination, and so forth (Leiter and Maslach, 2008; Yao et al., 2015).

The current study takes burnout as a three-dimensional variable, namely: emotional exhaustion, which refers to the feeling of physical or mental tiredness at work (Maslach and Leiter, 2017); depersonalization, referring to those who show impersonal reactions to their colleagues, and reduced accomplishment; refers to those who feel that they have little or no feeling about their achievements (Schaufeli et al., 2017).

The mismatch in effort-reward ratio ends in burnout (Leiter and Maslach, 2008), increased absenteeism, and lower performance (Baruch-Feldman et al., 2002). A loss of feelings about co-workers increases tiredness, and dissatisfaction toward growth at work are some of the indicators of burnout of an employee at work (Schaufeli and Greenglass, 2001; Schaufeli and Bakker, 2004; Leiter and Maslach, 2008).

The ERI framework with burnout provides a valuable approach to study toxic elements (terrorism) in the work environment. It suggests that high effort and low reward imbalance may have enduring effects, causing a gradual depletion of individuals' emotional resources and well-being (Shirom, 1989; Peter et al., 1998; Kivimäki and Siegrist, 2016). Therefore, the study proposes the following hypothesis based on facets of burnout.

Hypothesis 1(a); High efforts and low rewards in work environments in terrorism-ridden areas will be significantly associated with emotional exhaustion.

Hypothesis 1(b); High efforts and low rewards in work environments in terrorism-ridden areas will be significantly associated with depersonalization.

Hypothesis 1(c); High efforts and low rewards in work environments in terrorism-ridden areas will be significantly associated with reduced accomplishment.

\section{ROLE OF ORGANIZATIONAL JUSTICE AS A MEDIATOR}

Organizational justice refers to employees' perceptions of fairness in the workplace (Greenberg, 1990). It represents an employee's desire to obtain, establish or indicate rules that are equally applicable throughout the organization. Uniform rules are valuable indicators of the fairness of procedural outcomes, interpersonal treatment, and more contemporary perspectives cast a broader net. Prior literature on the organization justice construct has focused on the degree to which employees view themselves as fairly treated, more recent theories consider employees' reactions to the treatment of others (Elovainio et al., 2005b; Ambrose and Schminke, 2009). According to the ERI conceptual framework, more research is required on the justice construct because it causes adverse effects due to the developing countries' employment conditions.

Moreover, the relationship between ERI and burnout is mediated by organizational justice (Elovainio et al., 2005a). The mismatch in efforts and reward fosters a sense of injustice. In the long run, the sense of injustice opens up room for rumination and leaves the employees in a state of neglect. Neglection is a source of depersonalization and emotional exhaustion. Unbalanced exchanges in contexts between efforts and rewards make the work more unpredictable. It emphasizes the adequacy of the effortreward ratio (Van den Bos and Lind, 2002; Elovainio et al., 2005a). When environmental uncertainty increases and effort-reward imbalance is high, employees are more likely to have lower wellbeing and symptoms of burnout. Hence, when organizational injustice stays, and terrorist incidents are at a high, one's desire is to keep alive with all one's resources. The following hypothesis are proposed based on the above context. 
H 2(a): Organizational justice will significantly mediate the relationship between effort-

reward imbalance and emotional exhaustion relationship.

H 2(b): Organizational justice will significantly mediate the relationship between effort-

reward and depersonalization relationship

H 2(c): Organizational justice will significantly mediate the relationship between effort-

reward and reduced accomplishment relationship.

\section{ROLE OF SENSITIVITY TO TERRORISM (STT) AS A MODERATOR}

Fear in the organizational context creates a similar impact on the personality of employees. However, not all employees are the same personality traits. Terror management theory suggests that organizations may decide to have comfort and avoid employees' thoughts of death. Terror management theory (TMT) posits that in general, incidents of terrorism cause stress and death related consequences, in particular, have mixed feelings of vulnerability (Greenberg et al., 1986). However, the degree of vulnerability may not remain the same for all employees. Some individuals may tend to be more sensitive and easily affected by a situation, while others may show a less sensitive reaction toward it (Lazarus, 1995). The indirect effects of terrorism, such as emotional harm, depersonalization, and reduced accomplishment, are widespread, damaging the well-being of employees (Burke and Mikkelsen, 2006; Schaufeli et al., 2017).

STT moderates the relationship between organizational injustice and facets of burnout. In the sense that higher benefits should be associated with lower job burnout in the study context. The reason behind this is when employees are in trouble, then they expect a reasonable effort-reward ratio from the employers. They also hope employers support them and provide guarded security and cognitive therapy when threats are outward. Therefore, in this study, STT is predicted to moderate the direct relationship between ERI-burnout and organizational injustice-burnout relationships. Thus, it is proposed:

Hypothesis 3(a); Sensitivity to terrorism will moderate the relationship between effort-reward imbalance and emotional exhaustion.

Hypothesis 3(b); Sensitivity to terrorism will moderate the relationship between effort-reward imbalance ratio and depersonalization.

Hypothesis 3(c); Sensitivity to terrorism will moderate the relationship between effort-reward imbalance ratio and reduced accomplishment.

Hypothesis 4(a); Sensitivity to terrorism will moderate the relationship between organizational injustice and emotional exhaustion.

Hypothesis 4(b); Sensitivity to terrorism will moderate the relationship between the organizational injustice ratio and depersonalization.

Hypothesis 4(c); Sensitivity to terrorism will moderate the relationship between organizational injustice and reduced accomplishment.

\section{METHODOLOGY-RESEARCH CONTEXT AND DATA COLLECTION}

The study aims to measure the effects of predictors and comprises data from terrorist-ridden areas. For instance, earlier research on terrorist incidents, in general, provides surface descriptions of the problem. Prior research on this subject is based on a single incident, its consequences focus on a western context (Ryan et al., 2003, p. 11). Besides, previous research on terrorism is relatively based in a stable environment, i.e., USA. Hence, in this study, through focused investigations, we analyzed the influence of terrorism and how it is affecting employees at work in the context of developing countries.

Two cities Quetta and Peshawar, are targeted for data collection since these cities sustained multiple terrorist incidents. The educational institutes make up the target population, whereas the purposive sampling method is used for data collection. We used purposive sampling to undertake an indepth analysis of the conceptual framework. The academic staff took part from the two sample cities (Peshawar and Quetta) following the Army Public School (APS) attack (December 2014). Sample respondents who were affected by the attack, directly and indirectly, form the study respondents. This helped to collect data from the organizations and employees to fulfill the study's aims.

A total of 950 survey questionnaires in the English language were distributed. At the start of data collection, people received a cover letter in the English language. This is the official language of the country and researchers use it for the purposes of studies. All the participants were assured of confidentiality and anonymity, and provided consent before their participation. Each participant completed a survey with items related to the effortreward imbalance, organizational justice, sensitivity to terrorism, emotional exhaustion, depersonalization, and lack of personal accomplishment. The questionnaire included demographics (such as sex, age, education, and employment period) and questions on study variables. The response rate was 45 percent (i.e., 432/950).

\section{SCALES AND MEASURES}

\section{Effort-Reward Imbalance}

Overall, 23 scale items were used to measure the effort-reward framework. This scale deals with three major components of ERI: effort, reward, and over-commitment (Siegrist et al., 1997). A six item scale measured the effort component, 11 questions measured the reward component. It was further split into three parts, namely; monetary fulfillment, status control, and esteem reward. In this research, we have used the effort and reward components of the ERI framework. All scales measured in this research used a five-point Likert scale.

\section{Organizational Justice}

A 6-item questionnaire measured the perceived overall justice (POJ) based on the work of (Lind, 2001) and (Colquitt and Shaw, 2005). The respondents answered the questionnaire by measuring the POJ scale to assess the personal justice experience and general fairness of the organization. The three items were 
TABLE 1 | Mean, standard deviations, correlations, and reliabilities.

\begin{tabular}{|c|c|c|c|c|c|c|c|c|c|c|c|c|c|}
\hline & Mean & S.D & 1 & 2 & 3 & 4 & 5 & 6 & 7 & 8 & 9 & 10 & 11 \\
\hline 1. Sex & 1.33 & 0.47 & 1.00 & & & & & & & & & & \\
\hline 2. Age & 2.72 & 1.13 & $-0.205^{\star \star}$ & 1.00 & & & & & & & & & \\
\hline 3. Education & 2.22 & 0.49 & 0.02 & $-0.096^{\star}$ & 1.00 & & & & & & & & \\
\hline 4. Experience & 2.37 & 1.14 & -0.08 & $0.098^{\star}$ & 0.08 & 1.00 & & & & & & & \\
\hline 5. Effort & 3.29 & 0.78 & $0.097^{\star}$ & $-0.157^{\star \star}$ & $0.109^{\star}$ & $0.118^{\star}$ & 0.81 & & & & & & \\
\hline 6. Reward & 3.41 & 0.77 & 0.08 & $-0.185^{\star \star}$ & $0.107^{\star}$ & 0.09 & $0.434^{\star *}$ & 0.92 & & & & & \\
\hline 7. OJ & 3.27 & 1.16 & $0.125^{\star \star}$ & $-0.202^{\star \star}$ & $0.135^{\star \star}$ & $0.252^{\star \star}$ & $0.393^{\star \star}$ & $0.322^{\star \star}$ & 0.93 & & & & \\
\hline 8. STT & 3.46 & 0.87 & 0.06 & $-0.102^{\star}$ & $0.103^{\star}$ & $0.184^{\star \star}$ & $0.252^{\star \star}$ & $0.280^{\star \star}$ & $0.354^{\star \star}$ & 0.79 & & & \\
\hline 9. EE & 2.51 & 0.95 & 0.01 & -0.06 & 0.05 & 0.04 & $0.125^{\star \star}$ & 0.08 & $0.404^{\star \star}$ & 0.09 & 0.92 & & \\
\hline 10. DP & 2.59 & 0.96 & -0.01 & -0.06 & -0.01 & 0.00 & 0.09 & $0.111^{*}$ & $0.333^{\star \star}$ & -0.01 & $0.403^{\star \star}$ & 0.91 & \\
\hline 11. PA & 2.56 & 1.13 & -0.02 & -0.06 & -0.01 & $0.102^{\star}$ & 0.09 & 0.08 & $0.495^{\star \star}$ & 0.04 & $0.297^{\star \star}$ & $0.322^{\star \star}$ & 0.96 \\
\hline
\end{tabular}

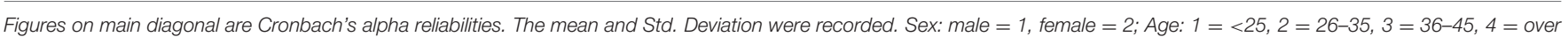

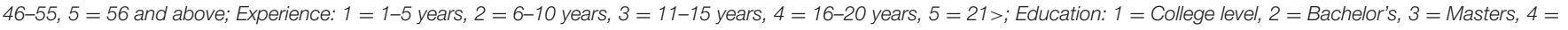
M.Phil. and above.

${ }^{\star *} p<0.01$ level.

${ }^{*} p<0.05$ level.

evaluated as employees' personal justice experiences; "Overall, I'm treated fairly by my organization;" "In general, I can count on this organization to be fair;" "In general, the treatment I receive around here is fair." The remaining three items assessed the fairness of the organization generally; "Usually, the way things work in this organization are not fair;" "For the most part, this organization treat its employees fairly;" "Most of the people who work here would say they are often treated unfairly."

\section{Sensitivity to Terrorism}

A 3-item scale measured STT to terrorism based on the work of Reade (2009). These items include "I seem to lose enthusiasm for work whenever I get news of terrorist incident," "I feel tenser at work when there is a fresh incident," and "I sometimes miss work or find it difficult to perform my job well due to the mood created by the terrorist incident."

\section{Maslach Burnout Inventory (MBI)}

The inventory questionnaire was developed by Maslach and Jackson (1981). It measured the three burnout components, i.e., emotional exhaustion (e.g., "I feel like I am at the end of my rope"), depersonalization (e.g., "I've become more callous toward co-workers' lives through my work"), and reduced accomplishment. Overall, a 22 item scale measured three facets of burnout inventory.

\section{Demographic Variables}

Respondents were asked to mention sex, age, education, and work experiences. The sex is categorized as (1) Male and (2) Female. Age groups were computed on the mean score using categories of (1) <25 years, (2) 26-34 years, (3) 35-44 years, (4) 45-54 years, (5) 55, and above. Education categories as (1) College-level, (2) Bachelor's, (3) Masters, and (4) M.Phil./M.S. Finally, experience is categorized as (1) 1-5 years, (2) 6-10 years, (3) 11-15 years, (4) 16-20 years, (5) 21>. We controlled for sex, age, education, and experience as these might influence ERI and burnout relationship.

In Table 1, the results stand for mean, std. Deviations, intercorrelations, and the reliabilities on the diagonal. Out of 432 questionnaires, 247 are reported male (57\%); 185 (43\%) are female, $138(32 \%)$ are reported between 35 and 44 years. Furthermore, 138 (32\%) of the sample had working experience of between 5 and 10 years, and 355 (82\%) of the sample comprised a master's degree.

\section{Analysis and Results}

All variables examined before the primary analysis-the normality of the entire data and detection of outliers. To analyze the direct, indirect, and total effects, we used the Process macro version described in Preacher and Hayes (2004). The procedures separately test the moderation and mediation hypotheses with 5,000 bootstraps used in the case of the mediator variable.

\section{Factor Analysis}

Before testing the hypotheses, we used factor analysis to confirm the adequacy of selected variables in this context. The value of the KMO is.91 and Bartlett's test of sphericity is significant $(p<0.001)$. The analysis extracted seven factors based on the eigenvalue greater than 1 accounting for $67.84 \%$. Factor 1 formed of eight items explained $25.13 \%$ of the variance with loadings from 0.825 to 0.906 . Factor 2 consists of 11 items that explain $14.88 \%$ of the variance with loadings from 0.644 to 0.822 . Factor 3 comprised of seven items that explained $8.70 \%$ of the variance with loadings from 0.716 to 0.858 . Factor 4 consists of seven items that explained $6.74 \%$ of the variance with loadings from 0.602 to 0.863 . Factor 5 comprises six items that explained $5.3 \%$ per cent of the variance with a factor from 0.750 to 0.868 . Factor 6 consists of six items that explain $4.16 \%$ per cent of the variance with loadings from 0.362 to 0.890 . Factor 7 consists of three items that account for $2.98 \%$ of the variance with loadings from 0.734 
TABLE 2 | Pattern matrix.

\begin{tabular}{|c|c|c|c|c|c|c|c|}
\hline Items & $\begin{array}{l}\text { Personal } \\
\text { acquisition }\end{array}$ & Reward & $\begin{array}{l}\text { Emotional } \\
\text { exhaustion }\end{array}$ & Depersonalization & $\begin{array}{l}\text { Org. } \\
\text { Justice }\end{array}$ & Effort & $\begin{array}{l}\text { Situation } \\
\text { to terror }\end{array}$ \\
\hline EF1 & & & & & & 0.362 & \\
\hline EF2 & & & & & & 0.755 & \\
\hline EF3 & & & & & & 0.89 & \\
\hline EF4 & & & & & & 0.792 & \\
\hline EF5 & & & & & & 0.429 & \\
\hline EF6 & & & & & & 0.454 & \\
\hline RW1 & & 0.692 & & & & & \\
\hline RW2 & & 0.774 & & & & & \\
\hline RW3 & & 0.789 & & & & & \\
\hline RW4 & & 0.739 & & & & & \\
\hline RW5 & & 0.75 & & & & & \\
\hline RW6 & & 0.75 & & & & & \\
\hline RW7 & & 0.644 & & & & & \\
\hline RW8 & & 0.67 & & & & & \\
\hline RW9 & & 0.79 & & & & & \\
\hline RW10 & & 0.669 & & & & & \\
\hline RW11 & & 0.822 & & & & & \\
\hline OJ1 & & & & & 0.833 & & \\
\hline OJ2 & & & & & 0.849 & & \\
\hline OJ3 & & & & & 0.868 & & \\
\hline OJ4 & & & & & 0.785 & & \\
\hline OJ5 & & & & & 0.75 & & \\
\hline OJ6 & & & & & 0.821 & & \\
\hline ST1 & & & & & & & 0.734 \\
\hline ST2 & & & & & & & 0.775 \\
\hline ST3 & & & & & & & 0.738 \\
\hline ME1 & & & 0.755 & & & & \\
\hline ME2 & & & 0.818 & & & & \\
\hline ME3 & & & 0.835 & & & & \\
\hline ME4 & & & 0.757 & & & & \\
\hline ME5 & & & 0.716 & & & & \\
\hline ME6 & & & 0.84 & & & & \\
\hline ME7 & & & 0.858 & & & & \\
\hline MD1 & & & & 0.849 & & & \\
\hline MD2 & & & & 0.863 & & & \\
\hline MD3 & & & & 0.829 & & & \\
\hline MD4 & & & & 0.602 & & & \\
\hline MD5 & & & & 0.731 & & & \\
\hline MD6 & & & & 0.843 & & & \\
\hline MD7 & & & & 0.638 & & & \\
\hline MP1 & 0.895 & & & & & & \\
\hline MP2 & 0.847 & & & & & & \\
\hline MP3 & 0.847 & & & & & & \\
\hline MP4 & 0.843 & & & & & & \\
\hline MP5 & 0.825 & & & & & & \\
\hline MP6 & 0.887 & & & & & & \\
\hline MP7 & 0.906 & & & & & & \\
\hline MP8 & 0.876 & & & & & & \\
\hline
\end{tabular}

to 0.775 . The whole analysis found seven clear patterns, and all are independent of one another (please see Table 2).

\section{Hypotheses Testing Direct Effects}

The relationship between ERI ratio and emotional exhaustion (EE), Depersonalization (DP), and reduced accomplishment (PA) were tested separately. All relationships are significant with $B=0.15, P<0.00$ for ERI and EE; $B=0.11, P<0.06$ for ERI and DP; and $B=0.13, P<0.05$ for ERI and PA. The relationship between ERI and organizational justice (OJ) stands significant at $B=0.59$ and $P<0.005$. The path from $\mathrm{OJ}$ to all dimensions of stress such as EE, DP, and PA was tested. In general, all direct hypotheses after investigation were found to be significant between $\mathrm{OJ}$ and $\mathrm{EE}\left(B=0.33 ; p<0.05^{* *}\right)$, between OJ and DP $\left(B=0.27 ; p<0.05^{* *}\right)$, between OJ and PA $(B=0.48$; $p<0.05^{* *}$ ) (see Table 3).

\section{Indirect Effects}

The data supported hypothesis 2(a) regarding OJ's mediating effect between the ERI ratio and EE. The indirect effect of the ERI ratio, via OJ, was significant on $\mathrm{EE}(B=0.589 ; p<0.001)$. The mediation results used Preacher and Hayes (2004) bootstrapping method and confirmed that $\mathrm{OJ}$ mediates the relationship between ERI ratio and EE.

The data supported hypothesis 2(b) regarding OJ's mediating effect between ERI ratio and DP. The indirect effect of ERI ratio, via OJ was significant on DP $(B=0.561 ; p<0.001)$. The data supported hypothesis 2 (c) regarding the mediating effect of organizational justice (OJ) between the ERI ratio and PA. The indirect effect of ERI, via OJ was significant on $\mathrm{EE}$ (beta $=0.591$; $p<0.001$ ) (see Table 4).

\section{Interaction Effects}

The data supported Hypothesis 3(a) about the moderating effect of the STT on the direct relationship between ERI ratio and EE. To rectify multicollinearity, we centered each of the two predictor variables, ERI and STT, by subtracting the sample mean from each variable before generating the interaction term. The interaction term was formed by multiplying the twocentered predictor variables: ERI*STT. The interaction term supported and showed a significant effect $(B=-0.189 ; p<$ 0.001). To establish the direction of the supported moderating effect of STT, we probed the significant interaction effect in a graph (see Figure 1). Overall, STT slightly dampens the negative relationship between ERI and EE in the graph.

The data supported Hypothesis 3(b) about the moderating effect of the STT on the direct relationship between ERI ratio and DP. The interaction term was formed by multiplying the two-centered predictor variables: ERI*STT. The data showed a significant effect $(B=-0.196 ; p<0.001)$. Moreover, to set up the direction of the supported moderating effect of STT, we probed the significant interaction effect in a graph (see Figure 2). Overall, STT mildly dampens the negative relationship between ERI and DP in the graph.

The data supported Hypothesis 3(c) regarding the moderating effect of the STT on the direct relationship between ERI ratio and PA. The interaction term was formed by multiplying the two-centered predictor variables: ERI*STT. The data showed a significant effect $(B=-0.284 ; p<0.001)$. To set up the direction of the supported moderating effect of STT, we probed the significant interaction effect in a graph (see Figure 3). Overall, STT mildly dampens the negative relationship between ERI and PA in the graph. 
TABLE 3 | Summary of direct effects.

\begin{tabular}{|c|c|c|c|c|c|c|c|c|c|c|c|c|c|c|c|c|}
\hline & \multicolumn{4}{|c|}{ OJ } & \multicolumn{4}{|c|}{ EE } & \multicolumn{4}{|c|}{ DP } & \multicolumn{4}{|c|}{ PA } \\
\hline OJ & & & & & 0.33 & 9.16 & $0.00^{\star \star}$ & 0.17 & 0.27 & 7.32 & $0.00^{\star \star}$ & 0.11 & 0.48 & 11.80 & $0.00^{\star \star}$ & 0.24 \\
\hline
\end{tabular}

${ }^{* *} p<0.01$ level.

${ }^{*} p<0.05$ level.

TABLE 4 | Summary of indirect effects.

\begin{tabular}{lcccc}
\hline & $\boldsymbol{B}$ & $\boldsymbol{T}$ & $\boldsymbol{P}$ & $\boldsymbol{R}^{\mathbf{2}}$ \\
\hline $\mathrm{ERI} \rightarrow \mathrm{OJ} \rightarrow \mathrm{EE}$ & 0.589 & 8.85 & $0.00^{\star \star *}$ & 0.16 \\
$\mathrm{ERI} \rightarrow \mathrm{OJ} \rightarrow \mathrm{DP}$ & 0.561 & 8.65 & $0.00^{\star \star}$ & 0.15 \\
$\mathrm{ERI} \rightarrow \mathrm{OJ} \rightarrow \mathrm{PA}$ & 0.591 & 8.95 & $0.00^{* \star}$ & 0.17 \\
\hline${ }^{* \star} p<0.01$ level. & & & & \\
${ }^{*} p<0.05$ level. & & & & \\
${ }^{* \star} p<0.001$ level. & & & &
\end{tabular}

TABLE 5 | Summary of moderating effects.

\begin{tabular}{|c|c|c|}
\hline & $B$ & $P$ \\
\hline$\left.\mathrm{ER}\right|^{\star} \mathrm{S} T T^{\star} \mathrm{EE}$ & -0.18 & $0.00^{*}$ \\
\hline$\left.\mathrm{ER}\right|^{*} \mathrm{~S} T T^{*} \mathrm{DP}$ & -0.19 & $0.00^{\star *}$ \\
\hline$\left.\mathrm{ER}\right|^{\star} S T^{*}{ }^{\star} \mathrm{PA}$ & -0.28 & $0.00^{*}$ \\
\hline OJ*STT*DP & -0.10 & $0.00^{*}$ \\
\hline OJ*STT*PA & -0.15 & $0.00^{\star \star}$ \\
\hline
\end{tabular}

${ }^{* *} p<0.01$ level.

${ }^{*} p<0.05$ level.

Hypothesis 4(a) about the moderating effect of the STT on the direct relationship between OJ and EE was not supported. Therefore, it is not reported here.

Hypothesis 4(b) regarding the moderating effect of the STT on the direct relationship between OJ and DP was supported. The interaction term was formed by multiplying the two centered predictor variables: OJ*STT. The data showed a significant effect $(B=-0.107 ; p<0.01)$. To establish the direction, we probed the significant interaction effect (see Figure 4). Overall, STT somewhat dampens the negative relationship between OJ and DP in the graph.

The data supported Hypothesis 4(c) about the moderating effect of the STT on the direct relationship between OJ and PA. The interaction term was formed by multiplying the two centered predictor variables: OJ*STT. The data showed a significant effect $(B=-0.17 ; p<0.001)$. To establish the direction, we probed the significant interaction effect (see Figure 5). Overall, STT slightly dampens the negative relationship between $\mathrm{OJ}$ and DP in the graph. A summary of the moderating effects is presented in Table 5.
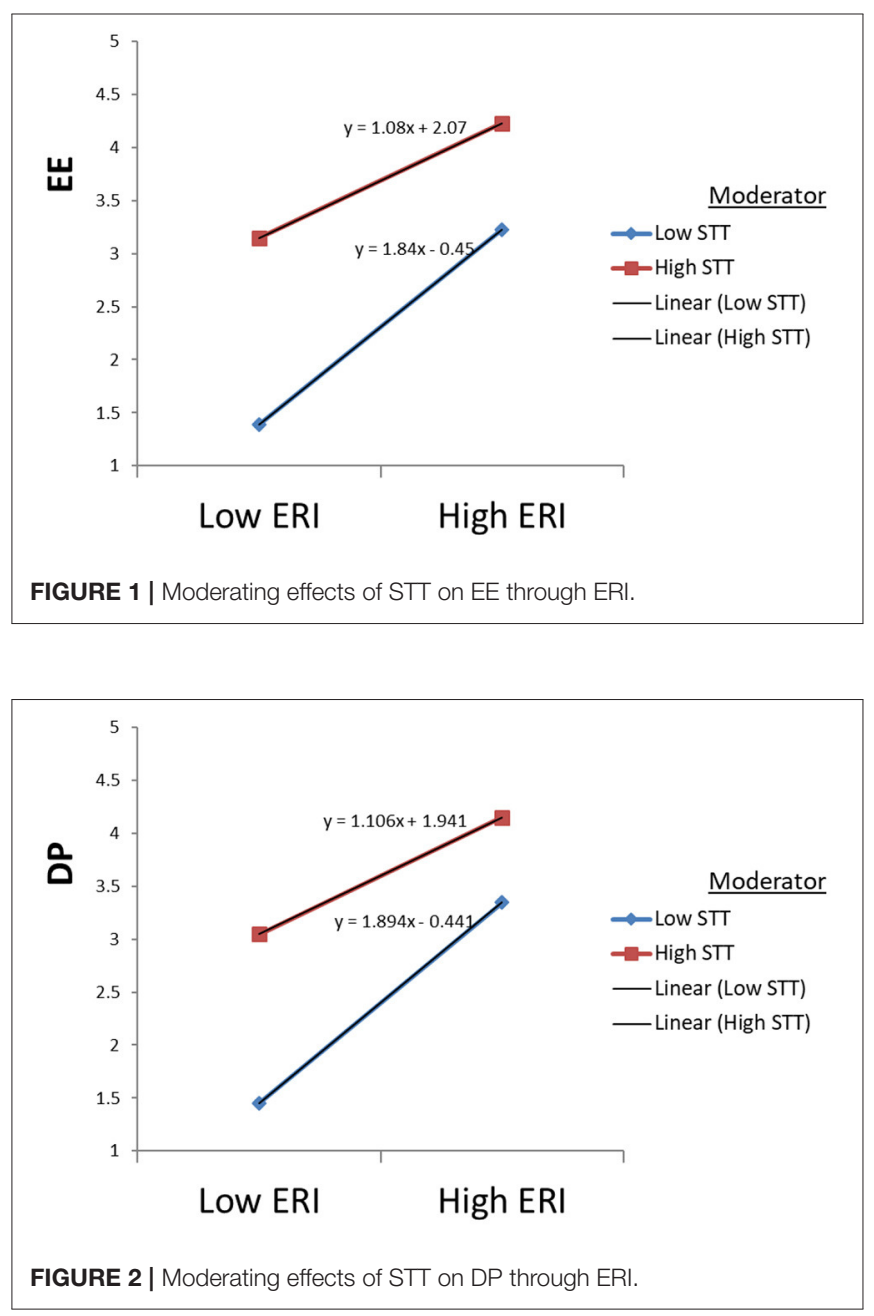

\section{DISCUSSION AND CONCLUSION}

This study formulated a framework of suggestions for future directions in research (Bader et al., 2015; Soomro et al., 2018) and has successfully tested the ERI framework (Siegrist, 2002) to examine its impact on burnout. Three facets of burnout, including emotional exhaustion, depersonalization, and reduced personal acquisition were tested separately (Maslach and Jackson, 1981; Maslach, 2017). The motives surrounding all variables, including outcome, are thoroughly explained in the literature review. The results provided significant support for the proposed 


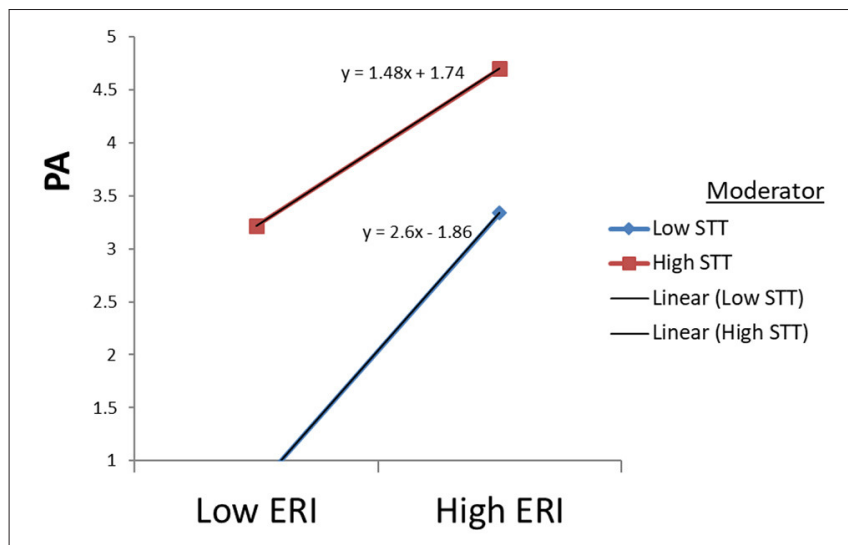

FIGURE 3 | Moderating effects of STT on PA through PA.

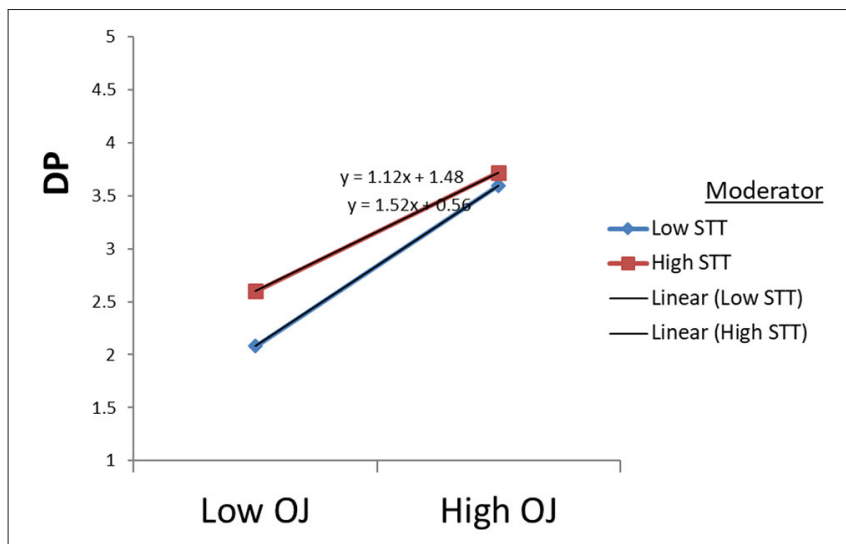

FIGURE 4 | Moderating effects of STT on DP through OJ.

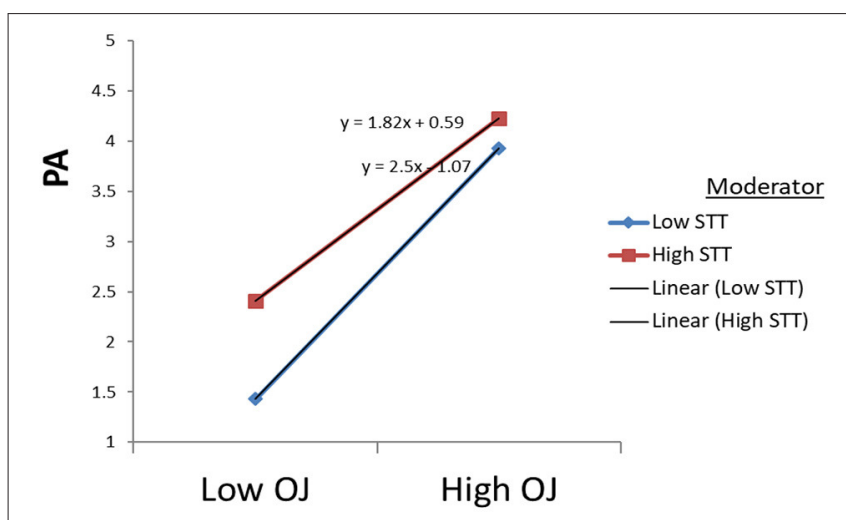

FIGURE 5 | Moderating effects of STT on PA through OJ.

hypothesis in the study context, within the proposed theoretical framework. The framework examines the relationship between effort-reward imbalance, resultant job stress, and its impact on three facets of job burnout in terrorist-ridden areas. In the findings section, we contribute to literature on burnout by linking the crucial yet under-researched construct of the effortreward imbalance for employees working in terrorist-ridden areas. This is one of the few studies that investigated the ERI framework using organizational justice as a mediator, STT as a moderator, and employee exhaustion, depersonalization, and reduced accomplishment as an output variable. Bader and Berg (2013) suggest the relevance of considering the STT variable for risky contexts.

Confirmation of hypothesis 1 about the relationship between ERI and emotional exhaustion, depersonalization, and reduced accomplishment in the study supports the argument that high effort and low rewards ratios lead to increased burnout among employees. The effort-reward imbalance framework suggests that failed reciprocity, in terms of high cost and low gain, increases job burnout, which has adverse effects on well-being (Siegrist et al., 1997). In existing research, employee higher efforts at the workplace cause their health as they receive no appropriate rewards in return. Under those circumstances, the feeling of physical danger and mental tiredness is pervasive in dangerous areas (Bader and Manke, 2018; Soomro et al., 2020). According to the literature, Bader and Berg (2014) also reported a significant negative relationship between sensitivity to terrorism, with compensation for expatriates $\left(-0.113^{*}\right)$. In this research, high efforts in the workplace in this context cause significant risk to employees' health and well-being. Moreover, Figures 15 describe the considerable effect of STT, which is weak for low sensitive employees and strong for high STT employees. Hence, the higher the sensitivity to terrorism, the higher the effect. It straightens the research on employee sensitivity working in terrorist-ridden areas.

The results support the hypotheses of the indirect effects of ERI on emotional exhaustion, cynicism, and reduced accomplishment through organizational justice. According to the ERI framework, uncertainty in terrorism-ridden areas creates a disturbance that makes it volatile for employees when working. Hence for employees looking for fair organizational policies, failure to do this may have adverse effects. Table 4 describes significant indirect effects. It is essential to understand that ERI wire organization justice is related to three facets of employee burnout. Organizational justice is a critical variable of the equation and is an appropriate way to test employee burnout in terrorism-ridden areas.

An uncertain environment underlies this indirect relationship in the context of this study. Firstly, uncertainty may be associated with the increased vulnerability of employees who attend their offices daily. Secondly, this uncertainty is sometimes resorting more frequently to determine the rewards received' adequacy, considering working in these contexts. Finally, the situation of risk as it is simultaneously uncontrollable could trigger attributive processes that would lead to saying the unfair organizational justice for the mismatch of effort-reward imbalance, which further affects the facets of employees' job burnout.

The data also support hypothesis 3, on the moderating effect of STT on the relationship between ERI ratio and three facets of job burnout. Thus accumulating evidence for the moderating hypothesis of the ERI framework, as also described 
by prior studies (Hämmig et al., 2012; Montano et al., 2016). In this study, results showed the weaker negative value of the interaction, which supports the idea that employees with higher sensitivity to terrorism show more signs of emotional exhaustion, depersonalization, and reduced accomplishment than employees with low sensitivity to terrorism, who show fewer effects. Overall, STT strengthens the relationship between the ERI ratio and facets of burnout.

Terrorism has received greater attention in business and management research after 9/11 (Howie, 2007; Soomro, 2019). It has a significant impact on many life characteristics, including employees' attitudes and behavior when working in high risk areas. Mainly, people living in ongoing terrorist-ridden regions have the lowest standard conditions of living and working (Trifiletti et al., 2017). The analysis of the present study is unique and adds scholarship to existing literature on terrorism stressors and job stressors. Overall, the data provide excellent support for the empirical investigation of terrorism and work stressors.

This research highlights the importance of effort-reward imbalance and organizational justice in risky areas. The success of staff working in these areas is a complex phenomenon, and although has not been extensively researched to date, there is still room to explain these phenomena in detail. This study is an early attempt to analyze the relationship between the ERI framework, sensitivity to terrorism, and emotional exhaustion, depersonalization, and lack of personal accomplishment at work separately. The study's findings will lead to future research on this

\section{REFERENCES}

Ahola, K., Toppinen-Tanner, S., Huuhtanen, P., Koskinen, A., and Väänänen, A. (2009). Occupational burnout and chronic work disability: an eight-year cohort study on pensioning among Finnish forest industry workers. J. Affect. Disord. 115, 150-159. doi: 10.1016/j.jad.2008.09.021

Ambrose, M. L., and Schminke, M. (2009). The role of overall justice judgments in organizational justice research: a test of mediation. J. Appl. Psychol. 94:491. doi: $10.1037 / \mathrm{a} 0013203$

Bader, B., and Berg, N. (2013). An empirical investigation of terrorism-induced stress on expatriate attitudes and performance. J. Int. Manag. 19, 163-175. doi: 10.1016/j.intman.2013.01.003

Bader, B., and Berg, N. (2014). The influence of terrorism on expatriate performance: a conceptual approach. Int. J. Human Res. Manag. 25, 539-557. doi: 10.1080/09585192.2013.814702

Bader, B., and Manke, B. (2018). "The impact of terrorism on the workplace,". Violence Abuse Around Organ, 1st Edn. Routledge. 103-126. doi: $10.4324 / 9781315194868$

Bader, B., Schuster, T., and Dickmann, M. (2015). Special issue of International Journal of Human Resource Management: danger and risk as challenges for HRM: how to manage people in hostile environments. Int. J. Hum. Resourc. Manag. 26:1038116. doi: 10.1080/09585192.2015.1038116

Baruch-Feldman, C., Brondolo, E., Ben-Dayan, D., and Schwartz, J. (2002). Sources of social support and burnout, job satisfaction, and productivity. J. Occupat. Health Psychol. 7:84. doi: 10.1037/1076-8998.7.1.84

Bliese, P. D., Edwards, J. R., and Sonnentag, S. (2017). Stress and well-being at work: a century of empirical trends reflecting theoretical and societal influences. J. Appl. Psychol. 102:389. doi: 10.1037/apl0000109

Brandon, S. E., and Silke, A. P. (2007). Near-and long-term psychological effects of exposure to terrorist attacks. Psychol. Terrorism 13, 175-193. doi: 10.1093/med:psych/9780195172492.003.0013 significant issue faced by the world and conceptualize sensitivity to terrorism individually, enabling us to see its adverse effects and mitigate them in organizations operating in high risk areas.

\section{DATA AVAILABILITY STATEMENT}

The datasets presented in this article are not readily available because the data is highly confidential and cannot be shared as it may create a threat to the concerned workers. Requests to access the datasets should be directed to shuaib.ahmed@iba-suk.edu.pk.

\section{ETHICS STATEMENT}

The studies involving human participants were reviewed and approved by University ethics committee. The patients/participants provided their written informed consent to participate in this study.

\section{AUTHOR CONTRIBUTIONS}

SASo, XHX, and AAG contributed to the design and implementation of the research, to the analysis of the results, and to the writing of the manuscript. SASh significantly helped us address the reviewer's comments in the manuscript. The author has made substantial contribution in data collection and revision of manuscript. He contributed in drafting the paper and also in interpretation of analysis part. All authors contributed to the article and approved the submitted version.

Burke, R. J., and Mikkelsen, A. (2006). Burnout among Norwegian police officers: potential antecedents and consequences. Int. J. Stress Manag. 13:64. doi: 10.1037/1072-5245.13.1.64

Canetti-Nisim, D., Halperin, E., Sharvit, K., and Hobfoll, S. E. (2009). A new stress-based model of political extremism personal exposure to terrorism, psychological distress, and exclusionist political attitudes. J. Conflict Resolut. 53, 363-389. doi: 10.1177/0022002709333296

Carnall, C. (2018). Managing Change. London: Routledge. doi: $10.4324 / 9781315122779$

Colquitt, J. A., and Shaw, J. C. (2005). "How should organizational justice be measured?" in Handbook of Organizational Justice, eds J. Greenberg and J. A. Colquitt (Lawrence Erlbaum Associates Publishers), 113-152.

Czinkota, M. R., Knight, G., Liesch, P. W., and Steen, J. (2010). Terrorism and international business: a research agenda. J. Int. Bus. Stud. 41, 826-843. doi: $10.1057 /$ jibs.2010.12

De Jonge, J., and Dormann, C. (2017). Why is my job so stressful? Characteristics, processes and models of stress at work. Introd. Work Organ. Psychol. Int. Perspective 2017, 80-101. doi: 10.1002/9781119168058.ch5

De Jonge, J., Van Der Linden, S., Schaufeli, W., Peter, R., and Siegrist, J. (2008). Factorial invariance and stability of the effort-reward imbalance scales: A longitudinal analysis of two samples with different time lags. Int. J. Behav. Med. 15:62. doi: 10.1007/BF03003075

Elovainio, M., Forma, P., Kivimäki, M., Sinervo, T., Sutinen, R., and Laine, M. (2005a). Job demands and job control as correlates of early retirement thoughts in Finnish social and health care employees. Work Stress 19, 84-92. doi: 10.1080/02678370500084623

Elovainio, M., van den Bos, K., Linna, A., Kivimäki, M., Ala-Mursula, L., Pentti, J., et al. (2005b). Combined effects of uncertainty and organizational justice on employee health: testing the uncertainty management model of fairness judgments among Finnish public sector employees. Social Sci. Med. 61, 2501-2512. doi: 10.1016/j.socscimed.2005.04.046 
Fischer, P., Greitemeyer, T., Kastenmüller, A., Jonas, E., and Frey, D. (2006). Coping with terrorism: the impact of increased salience of terrorism on mood and self-efficacy of intrinsically religious and nonreligious people. Personal. Soc. Psychol. Bullet. 32, 365-377. doi: 10.1177/0146167205282738

Greenberg, J. (1990). Looking fair vs. being fair: managing impressions of organizational justice. Res. Organ. Behav. 12, 111-157.

Greenberg, J., Pyszczynski, T., and Solomon, S. (1986). The causes and consequences of a need for self-esteem: a terror management theory. Public Self Private Self 189, 189-212. doi: 10.1007/978-1-4613-9564-5_10

Hämmig, O., Brauchli, R., and Bauer, G. F. (2012). Effort-reward and work-life imbalance, general stress and burnout among employees of a large public hospital in Switzerland. Swiss Med. Wkly 142, 135-147. doi: 10.4414/smw.2012.13577

Harlow, E., and Lawler, J. (eds.). (2018). Management, Social Work and Change. Routledge. doi: 10.4324/9781315187495

Hobfoll, S. E., Hall, B. J., Canetti-Nisim, D., Galea, S., Johnson, R. J., and Palmieri, P. A. (2007). Refining our understanding of traumatic growth in the face of terrorism: moving from meaning cognitions to doing what is meaningful. Appl. Psychol. 56, 345-366. doi: 10.1111/j.1464-0597.2007.00292.x

Howie, L. (2007). The terrorism threat and managing workplaces. Disast. Prevent. Manag. Int. J. 16, 70-78. doi: 10.1108/09653560710729820

Kivimäki, M., and Siegrist, J. (2016). "Work stress and cardiovascular disease: reviewing research evidence with a focus on effort-reward imbalance at work," in Work Stress and Health in a Globalized Economy. (London: Springer), 89-101. doi: 10.1007/978-3-319-32937-6_5

Klein, J., Grosse, F. K., Blum, K., Siegrist, J., and dem Knesebeck, O. V. (2010). Effort-reward imbalance, job strain and burnout among clinicians in surgery. Psychotherapie Psychosomatik Medizinische Psychol. 60, 374-379. doi: 10.1055/s-0029-1246173

Labrague, L. J., McEnroe-Petitte, D. M., Gloe, D., Tsaras, K., Arteche, D. L., and Maldia, F. (2017). Organizational politics, nurses' stress, burnout levels, turnover intention and job satisfaction. Int. Nurs. Rev. 64, 109-116. doi: 10.1111/inr.12347

Lange, S., Agarkova, I., Perriard, J. C., and Ehler, E. (2005). The sarcomeric Mband during development and in disease. J. Muscle Res. Cell Motil. 26, 375-379. doi: 10.1007/s10974-005-9019-4

Lazarus, R. S. (1995). Psychological stress in the workplace. Occupat. Stress Handb. 1, 3-14. doi: 10.1201/9781003072430-2

Leiter, M. P., and Maslach, C. (2008). Early predictors of job burnout and engagement. J. Appl. Psychol. 93, 498-512. doi: 10.1037/0021-9010.93.3.498

Lind, E. A. (2001). "Fairness heuristic theory: justice judgments as pivotal cognitions in organizational relations," in Advances in Organizational Justice, eds J. Greenberg and R. Cropanzano (Stanford University Press), 56-88.

Malik, O. F., Abdullah, H., and Uli, J. A. (2014). The effects of terrorism on work attitudes and behaviors: a literature review and a proposed model. J. Aggr. 6, 143-163. doi: 10.1108/JACPR-04-2013-0012

Marmot, M. (2015). The health gap: the challenge of an unequal world. Lancet 386, 2442-2444. doi: 10.1016/S0140-6736(15)00150-6

Maslach, C. (2017). Finding solutions to the problem of burnout. Consulting Psychol. J. Practice Res. 69:143. doi: 10.1037/cpb0000090

Maslach, C., and Jackson, S. E. (1981). The measurement of experienced burnout. J. Org. Behav. 2, 99-113. doi: 10.1002/job.4030020205

Maslach, C., and Leiter, M. P. (2017). New insights into burnout and health care: strategies for improving civility and alleviating burnout. Medical Teacher 39, 160-163. doi: 10.1080/0142159X.2016.1248918

Montano, D., Li, J., and Siegrist, J. (2016). "The measurement of Effort-Reward Imbalance (ERI) at work," in Work Stress and Health in a Globalized Economy (London: Springer), 21-42. doi: 10.1007/978-3-319-32937-6_2

Peter, R., Alfredsson, L., Hammar, N., Siegrist, J., Theorell, T., and Westerholm, P. (1998). High effort, low reward, and cardiovascular risk factors in employed Swedish men and women: baseline results from the WOLF Study. J. Epidemiol. Commun. Health 52, 540-547. doi: 10.1136/jech.52.9.540

Preacher, K. J., and Hayes, A. F. (2004). SPSS and SAS procedures for estimating indirect effects in simple mediation models. Behav. Res. Methods Instr. Comput. 36, 717-731. doi: 10.3758/BF03206553
Reade, C. (2009). Human resource management implications of terrorist threats to firms in the supply chain. Int. J. Phys. Distr. Logist. Manag. 39, 469-485. doi: 10.1108/09600030910985820

Ryan, A. M., West, B. J., and Carr, J. Z. (2003). Effects of the terrorist attacks of $9 / 11 / 01$ on employee attitudes. J. Appl. Psychol. 88:647. doi: 10.1037/0021-9010.88.4.647

Schaufeli, W. B., and Bakker, A. B. (2004). Job demands, job resources, and their relationship with burnout and engagement: a multi-sample study. J. Organ. Behav. 25, 293-315. doi: 10.1002/job.248

Schaufeli, W. B., and Greenglass, E. R. (2001). Introduction to special issue on burnout and health. Psychol. Health, 16, 501-510. doi: 10.1080/08870440108405523

Schaufeli, W. B., Maslach, C., and Marek, T. (2017). Professional Burnout: Recent Developments in Theory and Research. London: Taylor \& Francis. doi: $10.4324 / 9781315227979$

Shirom, A. (1989). "Burnout in work organizations," in International Review of Industrial and Organizational Psychology, eds C. L. Cooper and I. T. Robertson (Washington DC: John Wiley \& Sons), 25-48.

Siegrist, J. (2002). "Effort-reward imbalance at work and health," in Historical and Current Perspectives on Stress and Health (London: Emerald Group Publishing Limited), 261-291. doi: 10.1016/S1479-3555(02)02007-3

Siegrist, J. (2016). "Effort-reward imbalance model," in Stress: Concepts, Cognition, Emotion, and Behavior (Academic Press), 81-86. doi: 10.1016/B978-0-12-800951-2.00009-1

Siegrist, J., Klein, D., and Voigt, K. H. (1997). Linking sociological with physiological data: the model of effort-reward imbalance at work. Acta Physiol. Scand. Suppl. 640, 112-116.

Siegrist, J., Starke, D., Chandola, T., Godin, I., Marmot, M., Niedhammer, I., et al. (2004). The measurement of effort-reward imbalance at work: European comparisons. Soc. Sci. Med. 58, 1483-1499. doi: 10.1016/S0277-9536(03)00351-4

Soomro, S. A. (2019). Four Essays on the Influence of Terrorism Stress and Job Stress on Employee Attitude and Behavior (PhD Thesis). Aix-Marseille, Marseille, France.

Soomro, S. A., Roques, O., and Ali, A. (2018). Exposure to terror and employees' behaviour; rumination as a mediator and POS as a moderator. Acad. Manag. Proc. 2018:11887. doi: 10.5465/AMBPP.2018.11887abstract

Soomro, S. A., Roques, O., and Ali, A. (2020). Fear of terror and employees' behaviour in terrorist-ridden areas. J. Aggres. Conflict Peace Res. 2020:489. doi: 10.1108/JACPR-04-2020-0489

Trifiletti, E., Pedrazza, M., Berlanda, S., and Pyszczynski, T. (2017). Burnout disrupts anxiety buffer functioning among nurses: a three-way interaction model. Front. Psychol. 8:1362. doi: 10.3389/fpsyg.2017.01362

Van den Bos, K., and Lind, E. A. (2002). "Uncertainty management by means of fairness judgments," in Advances in Experimental Social Psychology, Vol. 34 (London: Elsevier), 1-60. doi: 10.1016/S0065-2601(02)80003-X

Van Vegchel, N., De Jonge, J., Bosma, H., and Schaufeli, W. (2005). Reviewing the effort-reward imbalance model: drawing up the balance of 45 empirical studies. Soc. Sci. Med. 60, 1117-1131. doi: 10.1016/j.socscimed.2004. 06.043

Yao, A. Y., Jamal, M., and Demerouti, E. (2015). Relationship of challenge and hindrance stressors with burnout and its three dimensions. J. Personnel Psychol. 14, 203-212. doi: 10.1027/1866-5888/a000141

Conflict of Interest: The authors declare that the research was conducted in the absence of any commercial or financial relationships that could be construed as a potential conflict of interest.

Copyright (C) 2021 Soomro, Gadehi, Xu and Shaikh. This is an open-access article distributed under the terms of the Creative Commons Attribution License (CC BY). The use, distribution or reproduction in other forums is permitted, provided the original author(s) and the copyright owner(s) are credited and that the original publication in this journal is cited, in accordance with accepted academic practice. No use, distribution or reproduction is permitted which does not comply with these terms. 